\title{
Left Ventricular Outflow Tract Velocity Time Integral
}

National Cancer Institute

\section{Source}

National Cancer Institute. Left Ventricular Outflow Tract Velocity Time Integral. NCI

Thesaurus. Code C127569.

The integral of all of the flow velocities within the left ventricular outflow tract during ventricular systole. 